\title{
Adolescents' preparedness and motivation across the transition to post-comprehensive education
}

\section{Lazarides, Rebecca}

2017-04

Lazarides, R, Viljaranta , J , Ranta, M \& Salmela-Aro , K 2017 , ' Adolescents'

preparedness and motivation across the transition to post-comprehensive education ' ,

Contemporary Educational Psychology, vol. 49 , pp. 151-159 . https://doi.org/10.1016/j.cedpsych.2017.01.008

http://hdl.handle.net/10138/298947

https://doi.org/10.1016/j.cedpsych.2017.01.008

cc_by_nc_nd

acceptedVersion

Downloaded from Helda, University of Helsinki institutional repository.

This is an electronic reprint of the original article.

This reprint may differ from the original in pagination and typographic detail.

Please cite the original version. 


\section{Accepted Manuscript}

Adolescents' preparedness and motivation across the transition to post-comprehensive education

Rebecca Lazarides, Jaana Viljaranta, Mette Ranta, Katariina Salmela-Aro

PII:

$$
\text { S0361-476X(17)30010-3 }
$$

DOI: http://dx.doi.org/10.1016/j.cedpsych.2017.01.008

Reference: YCEPS 1597

To appear in:

$$
\text { Contemporary Educational Psychology }
$$

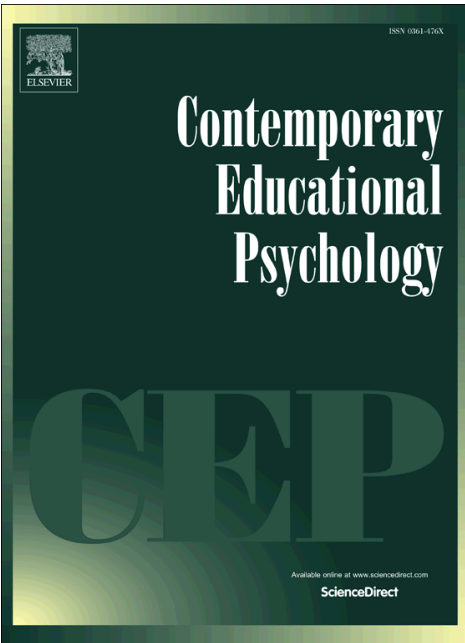

Received Date: 6 May 2016

Revised Date: $\quad 4$ January 2017

Accepted Date: $\quad 31$ January 2017

Please cite this article as: Lazarides, R., Viljaranta, J., Ranta, M., Salmela-Aro, K., Adolescents' preparedness and motivation across the transition to post-comprehensive education, Contemporary Educational Psychology (2017), doi: http://dx.doi.org/10.1016/j.cedpsych.2017.01.008

This is a PDF file of an unedited manuscript that has been accepted for publication. As a service to our customers we are providing this early version of the manuscript. The manuscript will undergo copyediting, typesetting, and review of the resulting proof before it is published in its final form. Please note that during the production process errors may be discovered which could affect the content, and all legal disclaimers that apply to the journal pertain. 
Adolescents' preparedness and motivation across the transition to post-comprehensive education Rebecca Lazarides ${ }^{1}$, Jaana Viljaranta ${ }^{3}$, Mette Ranta ${ }^{23}$ and Katariina Salmela-Aro ${ }^{23}$

${ }^{1}$ University of Potsdam, Germany; ${ }^{2}$ University of Helsinki, Finland; ${ }^{3}$ University of Jyväskylä, Finland

Author Note

Please direct correspondence to the corresponding author: ${ }^{1}$ Rebecca Lazarides, Department of Education, University of Potsdam, Germany; Karl-Liebknecht Straße 24-25, 14476 Potsdam, OT Golm, Germany, telephone: +49 (0) 331 9772132, rebecca.lazarides@ uni-potsdam.de.

\begin{abstract}
This longitudinal study aims to test the concept of transition preparedness in the context of educational transitions. The study investigates how adolescents' transition preparedness, conceptualized as their self-efficacy beliefs and their inoculation against setbacks, before an educational transition affect the adolescents' school value and effort related to educational goals after the transition through the effects on achievement goal orientations. Student data from three waves of a longitudinal study are used, first collected in 2004 (before the students' transition from comprehensive school to upper secondary education) and then collected twice after the transition.
\end{abstract}


The students included in the analyses are those who participated at all three measurement points $(N$ $=588 ; 49.5 \%$ girls; age $\left.M_{\mathrm{T} 1}=15.01, S D=0.13\right)$. Longitudinal structural equation modeling revealed that adolescents' self-efficacy beliefs (Time 1) positively predicted school value and effort (Time 3) through their effect on mastery goal orientation (Time 2). Furthermore, self-efficacy moderated the relation between performance-approach goal orientation (Time 1) on school value (Time 2). Results are discussed in terms of their relevance for enhancing adolescents' adaptive motivational development across educational transitions.

Keywords: Educational transitions, transition preparedness, self-efficacy beliefs, inoculation against setbacks, achievement goal orientations, school value 


\section{Introduction}

Educational transitions are critical stages in adolescents' academic development, as these stages are often associated with a decline in academic motivation (Jacobs, Lanza, Osgood, Eccles, \& Wigfield, 2002; Symonds, Dietrich, Chow, \& Salmela-Aro, 2016). Based on a model of preparedness for the transitions from school to working life (e.g., Dietrich, Parker, \& Salmela-Aro, 2012; Koivisto, Vuori, \& Vinokur, 2010; Salmela-Aro \& Vuori, 2015; Vuori \& Vinokur, 2005), high self-efficacy beliefs and inoculation against setbacks are individual characteristics that contribute to individuals' adjustment to life transitions. However, there is a need for longitudinal research to investigate whether this model can be applied to the school context. This longitudinal study examines how adolescents' preparedness for transitions, defined as self-efficacy beliefs and inoculation against setbacks (Koivisto et al., 2010), influence the adolescents' academic adjustment during the transition from comprehensive to post-comprehensive education. Academic adjustment was defined as academic effort and the valuing of learning in school (Hamm, Farmer, Lambert, \& Gravelle, 2014; Rueger, Malecki, \& Demaray, 2010). Studies often have focused on experimental designs when investigating individuals' preparedness for transitions (Salmela-Aro, Mutanen, \& Vuori, 2012; Vuori \& Vinokur, 2005). The significant contribution of this study to current research was to investigate the longitudinal relations between students' individual preparedness transitions and their academic adjustment. We used data from the Finnish educational system, where all adolescents have a similar basic general education until Grade 9 (comprehensive school) and, at the end of Grade 9, choose whether to apply for general or vocational upper secondary education (postcomprehensive education). 


\subsection{The concept of preparedness for transitions}

Referring to the model of preparedness for school-to-work transitions (Dietrich et al., 2012; Koivisto et al., 2010; Salmela-Aro et al., 2012; Salmela-Aro \& Vuori, 2015; Vuori \& Vinokur, 2005), it has been outlined that "both self-efficacy and inoculation against setbacks are intertwined ingredients of a cognitive-motivational construct referred to as job search preparedness" (Vuori \& Vinokur 2005, p. 278). Accordingly, preparedness has been measured on two scales: self-efficacy and inoculation against setbacks (Salmela-Aro et al., 2012). In general, self-efficacy beliefs are defined as individuals' confidence in their own ability to implement the actions required to accomplish certain tasks (Bandura, 1977, 1986). In the context of preparedness for transitions, selfefficacy beliefs are conceptualized as individual characteristics that enable adolescents to accomplish behaviors that are related to a successful life transition (Koivisto et al., 2010). Inoculation against setbacks refers to stress management skills that help individuals maintain goaloriented behavior when they face barriers (Meichenbaum, 1985; Salmela-Aro, Mutanen, Koivisto, \& Vuori, 2010). Current research mostly tested the concept of preparedness for transitions in the context of adolescents' school-to-work transitions (Koivisto et al., 2010; Salmela-Aro et al., 2012; Salmela-Aro \& Vuori, 2015; Vuori \& Vinokur, 2005) and only rarely adapted the concept to the school context (Dietrich et al., 2012). However, the application of the model to educational transitions might be of interest for current research because similar processes as in the context of school-to-work transitions may be assumed in the context of educational transitions. For example, one may assume that adolescents who have high self-efficacy beliefs related to educational choices, and thus who feel confident about their skills to choose an educational pathway that corresponds to their interests, may more easily develop high academic motivation in the years after the transition than students with low self-efficacy beliefs. Accordingly, one may assume that adolescents with high inoculation against setbacks are able to deal with the critical period of an educational transition 
more easily than students with low inoculation against setbacks and thus, may report higher motivation after the transition. Research has identified various aspects that are important for an adaptive development across educational transitions, such as autonomous motivation (Vasalampi et al., 2012) or the internal locus of control (Leontopoulou, 2006) and self-efficacy (Salmela-Aro \& Vuori, 2015). The theoretical model of preparedness for school-to-work transitions (Koivisto et al., 2010; Salmela-Aro et al., 2012; Vuori \& Vinokur, 2005), however, focuses on self-efficacy as a personal resource during life transitions. This is in line with research on the concept of academic buoyancy (Martin \& Marsh, 2008) that also describes adolescents' self-efficacy as a resource when dealing with academic setbacks. Based on these theoretical considerations, this study contributed to previous research by investigating whether the concept of preparedness can be applied to the context of educational transitions in school. In this study, preparedness for educational transitions was conceptualized as an overall adaptive construct that may enhance the adolescents' adaptive academic development across educational transitions.

\subsection{Preparedness for transitions, achievement goal orientations, school value, and effort}

Students' preparedness for transitions enhances the value that students attach to educational goals and thus facilitates the students' adjustment to educational transitions (Salmela-Aro \& Vuori, 2015). Regarding the school context, it may be assumed that the effects of preparedness for transitions on academic adjustment could be partially explained by the enhancement of adaptive achievement goal orientation. Achievement goal orientation has been defined as students' general orientation toward learning, that is, the kinds of goals they tend to choose and the kinds of outcomes they prefer in relation to studying (Niemivirta, 2002; Urdan, 1997). Individuals' goal orientations are often categorized as either mastery or performance goal orientations (Ames \& Archer, 1988; Elliott \& Dweck, 1988). A mastery goal orientation reflects a focus on learning and understanding 
(Pintrich, Conley, \& Kempler, 2003). Performance-approach goals are directed at demonstrating competence, while performance-avoidance goals are directed at avoiding the demonstration of incompetence (Elliot \& Harackiewicz, 1996). This study investigated how self-efficacy beliefs and inoculation against setbacks before the transition affect students' achievement goal orientations after the transition, and through these effects influence adolescents' academic adjustment. Previous studies that investigated individuals' inoculation against setbacks focused on the context of transitions to work (Koivisto et al., 2010; Vinokur, Price, \& Schul, 1995; Vinokur \& Schul, 1997). Findings indicated, for example, that an intervention programme that included the enhancement of inoculation against setbacks as a central component facilitated the participants' sense of mastery (Koivisto et al., 2010; Vinokur et al., 1995). There are, however, no previous longitudinal studies that investigated the relations between inoculation against setbacks and achievement goal orientations. Research on achievement goal theory proposed that the individual's mastery goal orientations are closely related to their sense of mastery (Ames, 1992; Ames \& Archer, 1988). Given that inoculation against setbacks have been shown to facilitate the individuals' sense of mastery (Koivisto et al., 2010; Vinokur et al., 1995), we assumed that inoculation against setbacks, in the school context, would be positively related to students' mastery goal orientation.

Furthermore, we assumed that high academic self-efficacy would foster the adoption of a mastery goal orientation (Diseth, 2011; Zimmerman, Bandura, \& Martinez-Pons, 1992). Elliot and Church (1997) described self-efficacy as antecedent of achievement goal orientations which in turn were assumed to affect achievement behavior. Accordingly, previous cross-sectional research has shown that self-efficacy beliefs were positively associated with mastery goal orientations (Diseth, 2011) and negatively with performance-approach (Schunk \& Swartz, 1993) and performanceavoidance goal orientations (Bong, 2001; Pajares, Britner, \& Valiante, 2000). However, only a few longitudinal studies examined these interrelations (Zimmerman et al., 1992). Thus, there is a need 
for longitudinal research that investigates how adolescents' preparedness for transitions is related to students' achievement goal orientations. Achievement goal orientations have been shown to be enhance adolescents' academic adjustment (see for example Elliot, Elliot, \& Dweck, 2005a) and it may be assumed therefore that adolescents' preparedness for transitions would be indirectly related to their academic adjustment through achievement goal orientations. This longitudinal study focused on school value and goal-related effort as indicators of academic adjustment. School value refers to the valuing of learning in school as enjoyable and useful (Niemivirta, 2004). It is similar to task value that refers to the quality of a task that contributes to the probability that an individual will select the task (Eccles, 2005). Effort in this study refers to the effort that adolescents invest to achieve their education-related goals (Salmela-Aro \& Nurmi, 1997). Both school value and effort have been shown to be positively related to mastery goal orientation (Pintrich, 2000; Schiefele \& Schaffner, 2015; Tuominen-Soini, Salmela-Aro, \& Niemivirta, 2012; Wentzel, 1996) and negatively to performance-avoidance goal orientation (Urdan \& Schoenfelder, 2006; Wolters, Shirley, \& Pintrich, 1996). Performance-approach goal orientation has been shown to positively correlate with task value (Bong, 2001) and negatively relates to academic effort (Pintrich, 2000).

\subsection{The present study}

In this longitudinal study, a transition preparedness framework (Dietrich et al., 2012; Koivisto et al., 2010; Salmela-Aro et al., 2012; Salmela-Aro \& Vuori, 2015; Vuori \& Vinokur, 2005) was applied to the context of educational transitions. The novel contribution of this study to current research was to longitudinally test the assumptions of the concept of preparedness for transitions in the school context. Preparedness for transitions is conceptualized as adolescents' selfefficacy and inoculation against setbacks (Vuori \& Vinokur, 2005). This study examined how adolescents' self-efficacy beliefs and inoculation against setbacks before an educational transition 
were related to the adolescents' achievement goal orientations one year after the transition, and how achievement goal orientations in turn were related to school value and effort 2 years after the transition. The study referred to domain-unspecific research questions as this approach allows to compare the findings with research in the context of school-to-work transitions (Koivisto et al., 2010; Salmela-Aro \& Vuori, 2015). Adolescents' self-efficacy was assessed on a context-specific base, conceptualized as adolescents' beliefs that they are capable of successfully planning and choosing their educational careers (Salmela $\square$ Aro \& Upadyaya, 2014).

Based on the reviewed research, specific hypotheses were tested in this study. It was expected that self-efficacy beliefs would be positively related to mastery goal orientation (Bong, 2004; Skaalvik, 1997) but negatively predict performance-approach (Schunk \& Swartz, 1993) and performance-avoidance goal orientation (Skaalvik, 1997). Inoculation against setbacks was expected to be positively related to students' mastery goal orientation (Vinokur \& Schul, 1997). Mastery orientation, in turn, was expected to be positively related to school value (Tuominen-Soini et al., 2012) and effort (Pintrich, 2000; Wentzel, 1996). Performance-approach goal orientation was expected to be negatively related to goal-related effort (Pintrich, 2000) and positively to school value (Bong, 2001). Performance-avoidance orientation was expected to be negatively related to school value (Tuominen-Soini et al., 2012), as well as effort (Pintrich, 2000). To gain a better understanding of the theoretical model that was tested in this study, we also examined whether selfefficacy beliefs and inoculation against setbacks are directly related to academic adjustment and thus, whether achievement goal orientations mediate the effects of self-efficacy and inoculation against setbacks on school value and goal-related effort. 


\section{Method}

\subsection{Sample}

This longitudinal study was based on student data from three waves of the [removed for reviewing purposes]. Student data were collected first in 2004 in 49 classes in all schools in one city in middle Finland. The second measurement point was during the first year of upper secondary education (2005), and the third was during the second year of upper secondary education (2006). For the present analyses, the data of those students who participated in all three measurement occasions $(N=588 ; 49.5 \%$ girls $)$ are used. The proportion of the full sample from the longitudinal study provided data at all three measurement points was $68.5 \%$. The cases with missing values did not differ from the cases that were included in the analyses in terms of their average self-reported achievement and the motivational criterion variables that were included in the study ${ }^{1}$.

The mean age of the 588 students was 15.01 years $(S D=0.13)$ at Time 1 . Most of these adolescents $(66.2 \%)$ attended the academic track, while $26.9 \%$ attended the vocational track at Time 2 (missing values: 7\%). The survey participants completed a self-report questionnaire during one 45-minute class session. Most students (93.9\%; 5.4\% missing) reported that they were native Finnish speakers. More than half of the participants $(n=50.7 \%)$ reported that their mothers were lower-white-collar workers (upper white collar: $18.4 \%$; blue collar: $12.6 \%$; others, such as selfemployed, unemployed, retired, or studying: 3.4\%; missing: 10.2\%). One quarter of participants $(n=$ $25.0 \%$ ) reported that their fathers were upper-white-collar workers (lower white collar: 17.5\%; blue collar: $28.4 \%$; others: $4.6 \%$; missing: $15.5 \%$ ).

\footnotetext{
${ }^{1}$ Achievement goal orientations at Time 2, school value and academic withdrawal at Time 3: Pillai's trace $-F(6,426)=$ $.469, p=.831$
} 


\subsection{Measures}

\subsubsection{Achievement}

Self-reported grade-point average (GPA) from the preceding spring term, for all subjects, was used from Time 1. Students' GPAs ranged from 4 (lowest) to 10 (highest). In Finnish studies, self-reports of academic performance have been found to be relatively reliable as self-reported GPA has been shown to correlate to actual grade point average with a correlation coefficient of .96 (Holopainen \& Savolainen, 2005).

\subsubsection{Self-efficacy related to educational choices}

Self-efficacy was assessed at Time 1 with a five-item scale based on Vuori and Vinokur (2005) scale. The seven-point Likert scale ranged from 1 (Very poorly) to 7 (Very well). The assessment included items such as, "How well do you think you can identify strengths and interests in you that benefit your future choice of educational and work career?" Reliability was $\square=.767$ (Time 1).

\subsubsection{Inoculation against setbacks}

Student-reported inoculation against setbacks was assessed at Time 1 with a four-item scale based on Vuori and Vinokur (2005) scale. The seven-point Likert scale ranged from 1 (Not at all) to 7 (Very many). An example item is: "Do you have ready-formed ideas or plans in case you face difficulties in your studies?" Reliability was $\square=.714$ (Time 1).

\subsubsection{Achievement goal orientations}

The adolescents' achievement goal orientation was assessed at Time 1 and Time 2 with subscales developed by Niemivirta (2002). Each achievement goal orientation was assessed with a 
three-item, seven-point Likert scale ranging from 1 (Not true at all) to 7 (Very true). An example item for mastery orientation is the following: "Acquiring new knowledge is an important goal for me in school." Reliability was $\square=.864$ (Time 1 ) and $\square=.872$ (Time 2). An example item for the performance-approach orientation assessment is the following: "An important goal for me in school is to do better than other students" (Time 1: $\square=.683$; Time 2: $\square=.724$ ). An example item for the performance-avoidance orientation assessment is the following: “It is important to me that I don't fail in front of other students" (Time 1: $\square=.818$; Time 2: $\square=.854$ ).

\subsubsection{School value}

The student-reported school value was assessed at Time 2 and Time 3 with a scale based on Niemivirta (2004) scale, which was oriented toward those of (Eccles et al., 1993). The scale consisted of three items that assessed students' perceptions regarding the importance, utility, and interestingness of school attendance and studying. The seven-point Likert scale ranged from 1 (Not true at all) to 7 (Very true). An example item for school value is the following: "I feel that studying and going to school are useless." All items were recoded, with high values indicating high school value (Time 2: $\square=.703$; Time $3: \square=.628$ ).

\subsubsection{Education-related personal goal effort}

Student-reported education-related personal goal effort was assessed at Time 2 and Time 3 with a two-item scale (Salmela-Aro \& Nurmi, 1997). The seven-point Likert scale ranged from 1 (Very little) to 7 (Very much). The participants were first asked to produce one personal goal related to education or working life, after which they appraised this goal according to effort. Items for education-related personal goal effort included the following: "How much time and effort have you 
spent on this goal?" and "To what extent have you worked for your goal?" (Time 2: $\square=.876$; Time 3: $\square=.905)$.

\subsection{Analytic strategy}

In the first step, scalar measurement invariance of the latent variables across time was tested. A measurement model with configural invariance was established (Table 1; step 1). Subsequently, factor loadings were set invariant across time (Table 1; step 2). Next, factor loadings and item intercepts were set invariant across time (Table 1; step 3; (Byrne, 1989). When testing whether the structure of an underlying construct varies across time or groups was tested, partial measurement invariance indicates that not all parameters are equivalent across the time points or among groups (Byrne, 1989). According to the statistical literature (Bagozzi \& Edwards, 1998; Byrne, 1989; Vandenberg \& Lance, 2000), at least partial metric invariance must be established in order for subsequent tests to be meaningful. However, the threats are that data-driven analyses are posed to the integrity of the research findings (Vandenberg \& Lance, 2000). In this study, we applied a conservative approach (Vandenberg \& Lance, 2000) by relaxing only a minority of the equality constraints on the loadings or intercepts in the process of testing the measurement model for time invariance (see the Appendix A).

The adolescents' self-efficacy related to educational choices and inoculation against setbacks at Time 1 was specified as a predictor of their achievement goal orientations at Time 2, while controlling for achievement goal orientations at Time 1. Achievement goal orientations at Time 2 were specified as predictors of school value and goal-related effort at Time 3, while controlling for school value and goal-related effort at Time 2. The hypothesized model is depicted in Figure 1 . The empirical model is depicted in Figure 2. Students' gender and GPA were included as control variables but are reported only in the tables. All predictors, as well as the residual variances of the 
corresponding variables across time, were allowed to correlate (Little, 2013). We furthermore examined whether achievement goal orientations mediated the effects of self-efficacy beliefs and inoculation against setbacks on school value and goal-related effort. ${ }^{2}$ To test for mediation, it was tested whether the proposed indirect effects led to a statistically significantly reduced direct effect of self-efficacy beliefs and inoculation against setbacks on school value and goal-related effort (Baron \& Kenny, 1986; Preacher \& Hayes, 2008).

Mplus version 7.0 was used for all analyses (Muthén \& Muthén, 1998-2010). Maximum likelihood estimation with robust standard errors and chi-square (MLR) was used. The TYPE = COMPLEX function of Mplus was used to correct standard errors and chi-square values for the nested structure of the student data, and classrooms were used as the cluster variable. Missing data were handled by using full-information maximum likelihood estimation (FIML). Following Tanaka (1993), the following criteria were employed to evaluate the goodness of fit of the models: YuanBentler scaled $\chi^{2}$ (YB $\chi^{2}$, mean-adjusted test-statistic robust to non-normality), the Tucker-Lewis index (TLI), the comparative fit index (CFI), the root mean square error of approximation (RMSEA), and the standardized root mean residual (SRMR). TLI and CFI values close to .95 (Hu \& Bentler, 1999), RMSEA values close to .06, and SRMR $\leq .08$ (Hu \& Bentler, 1999) were accepted as indicators of good model fit.

\footnotetext{
${ }^{2}$ In order to deepen our understanding of the functioning of preparedness for transitions within the relations between achievement goal orientation and effort/value, we also tested whether preparedness before the transition moderate the relations between achievement goal orientations before the transition on school value and effort after the transition. The findings are reported in the appendix B.
} 


\section{Results}

\subsection{Measurement model and invariance tests}

Model fit indices for each step of the measurement test procedure are displayed in Table 1. Partial measurement invariance across time was established (for further information see the Appendix A). The data showed a rather poor but still acceptable fit to the final measurement model according to the incremental fit indices (Table 1; step 4). The modification indices indicated that the measurement model of adolescents' self-efficacy related to educational choices contributed to the low fit of the measurement model. However, we did not change the measurement model and continued with the originally tested model. The range of the standardized latent factor loadings of this final model is reported in Table 2.

--Table 1--

--Table 2-

\subsection{Preliminary analyses}

Latent correlations between the study variables are displayed in Table 4. Boys reported significantly lower GPAs, lower performance-avoidance orientation (Time 2), and lower academic withdrawal (Time 2) but also reported lower mastery orientation (Time 2) and lower school value (Times 2 and 3) than girls. Adolescents' self-reported GPA at Time 1 was positively associated with performance-approach orientation (Time 1), mastery orientation (Times 1 and 2), and school value (Times 2 and 3). 


\subsection{Longitudinal effects of self-efficacy beliefs and inoculation against setbacks}

The data showed an acceptable fit to the model: $\chi^{2}(637, N=588)=1114.220, p<.001$, CFI $=.94, \mathrm{TLI}=0.93 ; \mathrm{RMSEA}=.036, \mathrm{SRMR}=.054$. The model is depicted in Figure 2. The standardized coefficients of this model are displayed in Table 5.

--Figure 2--

--Table 4--

The latent constructs in the model had moderate to high stability across time. According to statistical guidelines (Ferguson, 2009), $\beta \geq .20$ was considered to indicate low stability, $\beta \geq .50$ was considered to indicate moderate stability, and $\beta \geq .80$ was interpreted as indicating high stability. According to these guidelines, mastery (Time 1 -Time $2: \beta=.354, S E=.05, p<.001$ ), performanceapproach (Time 1-Time 2: $\beta=.452, S E=.05, p<.001$ ), performance-avoidance orientations (Time 1-Time 2: $\beta=.458, S E=.04, p<.001)$, goal-related effort (Time 2-Time 3: $\beta=.378, S E=.06, p<$ .001 ), and school value (Time $1-$ Time $2: \beta=.486, S E=.08, p<.001$ ) had moderate stability across time. Adolescents' self-efficacy beliefs at Time 1 positively predicted the students' mastery orientation $(\beta=.226, S E=.06, p<.001)$ and school value at Time $2(\beta=.225, S E=.05, p<.001)$. Self-efficacy beliefs at Time 1 negatively predicted performance-avoidance orientation $(\beta=-.134$, $S E=.06, p<.05)$. Analyses of indirect effects in the model showed that self-efficacy beliefs at Time 1 positively affected school value at Time 3 through their effect on mastery orientation at Time 2 $(\beta$ ind $=.051, S E=.02, p<.001,95 \%$ confidence interval $(\mathrm{CI})[0.017,0.069])$. The model explained statistically significant amounts of variance in goal-related effort (Time $2: R^{2}=.051, p<.05$; Time 3: $R^{2}=.208, p<.001$ ), school value (Time $2: R^{2}=.138, p<.001 ;$ Time $3: R^{2}=.458, p<.001$ ), mastery orientation (Time $2: R^{2}=.256, p<.001$ ), performance-approach (Time $2: R^{2}=.205, p<$ .001 ), and performance-avoidance orientation (Time $2: R^{2}=.267, p<.001$ ). 
In a next step, we tested a mediational model that included the direct effects of self-efficacy beliefs related to educational choices and inoculation against setbacks on school value and goalrelated effort. The model showed a similar fit compared to the full-mediation model, $\chi^{2}(635, \mathrm{~N}=$ $588)=1117.294, p<.001, \mathrm{CFI}=.94, \mathrm{TLI}=0.92 ; \mathrm{RMSEA}=.036, \mathrm{SRMR}=.053$. The findings showed that adolescents' self-efficacy beliefs and inoculation against setbacks did not statistically significantly predict students' school value at Time 3 (self-efficacy beliefs: $\beta=.058, S E=.04, p=$ .166 ; inoculation against setbacks: $\beta=.036, S E=.05, p=.497$ ) or goal-related effort at Time 3 (self-efficacy beliefs: $\beta=.112, S E=.07, p=.074$; inoculation against setbacks: $\beta=.030, S E=.07, p$ $=.658$ ) when the achievement goal orientations at Time 2 were included. When achievement goal orientations were excluded, adolescents' self-efficacy beliefs had a statistically significant direct effect on the students' goal-related effort $(\beta=.169, S E=.06, p<.01)$. Given the statistically significant indirect effects of self-efficacy beliefs on adolescents' school value and goal-related effort and the statistically significant direct effect of self-efficacy beliefs on goal-related effort when achievement goal orientations were excluded, the finding thus indicated that adolescents' mastery goal orientation mediated the effect of self-efficacy before the transition on goal-related effort 2 years after the transition.

\section{Discussion}

This study aimed to investigate how adolescents' preparedness for transitions, conceptualized as the adolescents' self-efficacy beliefs and their inoculation against setbacks before an educational transition, were related to the students' academic adjustment 2 years after the transition through their achievement goal orientations one year after the transition. The contribution of the study to current research is twofold: First, by applying the conceptual model of transitional preparedness (Koivisto, Vinokur, \& Vuori, 2011; Salmela-Aro et al., 2012) to the context of 
educational transitions, the study provided knowledge about the individual factors that enhance adolescents' adaptive academic development across educational transitions. Second, by using a three-wave longitudinal design to investigate these questions, the study contributed to previous research by providing knowledge about the underlying mechanisms that explain the functioning of self-efficacy beliefs and inoculation against setbacks during educational transitions.

The findings of this study demonstrated that adolescents who reported high self-efficacy beliefs before the transition reported high mastery orientation one year after the transition, which, in turn, led to high school value and high goal-related effort 2 years after the transition. Self-efficacy was indirectly related to school value and effort through the adolescents' mastery goal orientations. Mastery orientation therefore seems to act as a key variable for adaptive academic development during educational transitions. In this study, self-efficacy beliefs were assessed in terms of adolescents' beliefs that they were capable of successfully planning and choosing their educational careers (Salmela $\square$ Aro \& Upadyaya, 2014). This specific operationalization may be an explanation for the statistically non-significant relations between self-efficacy beliefs and performance-approach or performance-avoidance goal orientations. Adolescents' performance goal orientations in the context of academic learning have been shown to be related to their academic self-efficacy (Bandura, 1993; Zimmerman et al., 1992), but may not be affected by their self-efficacy related to educational choices. However, on a statistical level, the non-significant relations may also be partially explained by the relatively strong covariance between the performance goal orientations. When discussing the assessment of self-efficacy in this study, it also must be acknowledged that, according to the modification indices, the measurement model of adolescents' self-efficacy contributed decisively to the low fit of the measurement model. The measurement model could be elaborated in future studies, for example, by including items that refer to adolescents' beliefs about being able to explore occupations or study programs of interest. 
In contrast to our expectations, inoculation against setbacks before the educational transition did not significantly affect adolescents' achievement goal orientations or academic outcomes after the transition. There are several possible explanations for these findings. For example, the design of this study differed from previous experimental studies that investigated inoculation against setbacks and self-efficacy as integral components of an intervention programme (e.g., Koivisto et al., 2010; Salmela-Aro et al., 2012; Vinokur \& Schul, 1997). In this study, we investigated the separate effects of inoculation against setbacks and self-efficacy beliefs on academic adjustment using a longitudinal design and student questionnaire data. The analyses of the separate effects of self-efficacy beliefs and inoculation against setbacks indicated that inoculation against setbacks might play a subordinate role for students' academic adjustment during the educational transition. However, it may also be assumed that inoculation against setbacks are more relevant when facing setbacks during educational transitions (e.g., failing to score high on or failing to pass exams) than when dealing with the transition itself because inoculation against setbacks is defined as "anticipatory stress management skills that help an individual to maintain active, goal-oriented behavior and personal well-being when facing barriers or setbacks" (Koivisto et al. 2010, p. 872). Furthermore, research (Vuori \& Vinokur, 2005) indicated that inoculation against setbacks may be particularly important for psychological well-being (e.g. decrease of depressive symptoms). To investigate the relevance of inoculation against setbacks in times of educational transitions in greater detail, further longitudinal research is needed.

When interpreting the findings of this study, it is furthermore important to notice that adolescents' performance-approach and -avoidance orientations did not have statistically significant effects on the students' school value or goal-related effort. This finding contrasts previous results that indicated, for example, that performance-avoidance goal orientation is significantly negatively related to students' school value (Tuominen-Soini et al., 2012; Wolters et al., 1996) and academic 
effort (Urdan \& Schoenfelder, 2006) and that performance-approach orientation is significantly positively related with students' task value (Bong, 2001; Wolters et al., 1996). A possible explanation for the statistically non-significant effects of performance goal orientations on academic outcomes in this study may be the relatively strong covariance between the performance-approach and performance-avoidance orientations after the transition. A theoretical explanation for the nonsignificant findings in this study might be that in contrast to previous studies (Bong, 2001; Church, Elliot, \& Gable, 2001; Elliot \& Church, 1997), this study did not focus on specific domains, but on the general school context. Achievement goal theorists (Elliot, Elliot, \& Dweck, 2005b) have argued that achievement goal orientations might be situation-specific. Accordingly, strong intercorrelations between achievement goal orientations and other motivational variables (e.g., self-efficacy, task value) have been shown to exist particularly within domains (Bong, 2001). Whether or not this may, in particular, apply to performance goal orientations needs to be investigated further in future domain-specific longitudinal studies.

When analyzing the role of achievement goal orientations during educational transitions in greater detail, it may furthermore be useful to apply a multiple-goal perspective, taking into account that students may pursue a combination of goal orientations (Harackiewicz, Barron, Tauer, \& Elliot, 2002; Pintrich, 2000; Wormington \& Linnenbrink, 2016). Further, research on motivational profiles (Alexander \& Murphy, 1998; Tuominen-Soini, Salmela-Aro, \& Niemivirta, 2008, 2011; Viljaranta et al., 2016) may also contribute to the investigation of the role of adolescents' achievement goal orientations across educational transitions.

Summarizing the theoretical contribution of this study to previous research, the study showed that self-efficacy beliefs, which were previously described as a key component of adolescents' preparedness for transitions from school to work (Vuori \& Vinokur, 2005) can also be seen as an important component of adolescents' preparedness for educational transitions. 


\subsection{Limitations and future research}

When discussing and interpreting the findings of this study, several limitations must be considered. For example, the school value scale in this study had a relatively low reliability that may have led to an underestimation of the relationships between school value and the other variables in the model (Schmitt, 1996). The construct as school value was assessed with only three items in this study, and thus, more complex measures of adolescents' value of studying in school would strengthen the investigation of the relations that were tested in this study. Furthermore, although the analyses were corrected for the hierarchical structure of the data, it is important to consider the role of classroom context in students' motivational development (Eccles \& Wigfield, 2002). Another limitation is that we investigated only unidirectional effects. As some previous cross-sectional studies in the academic context have suggested that self-efficacy beliefs predict achievement goal orientations (e.g., Coutinho \& Neuman, 2008; Phillips \& Gully, 1997), it is important to examine in longitudinal studies the direction of the effects between achievement goal orientations and selfefficacy beliefs in greater detail. Furthermore, as motivational research has constantly emphasized the importance of a subject-specific viewpoint (Alexander, Murphy, \& Kulikowich, 1998; Murphy \& Alexander, 2000), a salient step to further develop the concept of transition preparedness may be the investigation of motivational processes across educational transitions in particular academic subjects.

The findings of this study are important for teachers and educators and provide knowledge about the individual factors that need to be addressed when preparing adolescents for educational transitions. This study contributed to the theoretical development of the model preparedness for transitions (Koivisto et al., 2010; Salmela-Aro et al., 2010; Salmela-Aro et al., 2012) by showing that the model can be applied to the context of educational transitions. Thus, the study facilitated a better understanding of how adolescents' adaptive motivational development can be enhanced 
across educational transitions. In terms of practical implications for teachers and educators, the findings may lead to the conclusion that it is important to create learning environments before an educational transition that prompt adolescents' self-efficacy beliefs related to educational choices, which may lead to the adoption of adaptive goal orientations after the transition and, in turn, enhance adolescents' valuing of learning in school after the transition. 
Acknowledgements

[Removed for reviewing purposes] 


\section{References}

Alexander, P. A., \& Murphy, P. K. (1998). Profiling the differences in students' knowledge, interest, and strategic processing. Journal of Educational Psychology, 90(3), 435-447. doi: $10.1037 / 0022-0663.90 .3 .435$

Alexander, P. A., Murphy, P. K., \& Kulikowich, J. M. (1998). What responses to domain-specific analogy problems reveal about emerging competence: A new perspective on an old acquaintance. Journal of Educational Psychology, 90(3), 397-406. doi: http://dx.doi.org/10.1037/0022-0663.90.3.397

Ames, C. (1992). Classrooms: Goals, structures, and student motivation. Journal of Educational Psychology, 84(3), 261-271.

Ames, C., \& Archer, J. (1988). Achievement goals in the classroom: Students' learning strategies and motivation processes. Journal of Educational Psychology, 80(3), 260-267.

Bagozzi, R. P., \& Edwards, J. R. (1998). A general approach for representing constructs in organizational research. Organizational Research Methods, 1(1), 45-87.

Bandura, A. (1977). Self-efficacy: toward a unifying theory of behavioral change. Psychological Review, 84(2), 191-215. doi: http://dx.doi.org/10.1037/0033-295X.84.2.191

Bandura, A. (1986). Social foundations of thought and action: A social cognitive theory: PrenticeHall, Inc.

Bandura, A. (1993). Perceived self-efficacy in cognitive development and functioning. Educational Psychologist, 28(2), 117-148. doi: 10.1207/s15326985ep2802_3

Baron, R., \& Kenny, D. (1986). The mediator-moderator distinction in social psychology: Conceptual, strategic, and statistical considerations. Journal of Personality and Social Psychology, 51(6), 1173-1182. 
Bong, M. (2001). Between-and within-domain relations of academic motivation among middle and high school students: Self-efficacy, task value, and achievement goals. Journal of Educational Psychology, 93(1), 23-34. doi: http://dx.doi.org/10.1037/0022-0663.93.1.23

Bong, M. (2004). Academic motivation in self-efficacy, task value, achievement goal orientations, and attributional beliefs. The Journal of Educational Research, 97(6), 287-298. doi: 10.3200/JOER.97.6.287-298

Byrne, B. M. (1989). Multigroup comparisons and the assumption of equivalent construct validity across groups: Methodological and substantive issues. Multivariate Behavioral Research, 24(4), 503-523. doi: 10.1207/s15327906mbr2404_7

Church, M. A., Elliot, A. J., \& Gable, S. L. (2001). Perceptions of classroom environment, achievement goals, and achievement outcomes. Journal of Educational Psychology, 93(1), 43-54. doi: http://dx.doi.org/10.1037/0022-0663.93.1.43

Coutinho, S. A., \& Neuman, G. (2008). A model of metacognition, achievement goal orientation, learning style and self-efficacy. Learning Environments Research, 11(2), 131-151. doi: $10.1007 / \mathrm{s} 10984-008-9042-7$

Dietrich, J., Parker, P., \& Salmela-Aro, K. (2012). Phase-adequate engagement at the post-school transition. Developmental Psychology, 48(6), 1575-1593. doi: http://dx.doi.org/10.1037/a0030188

Diseth, ̊̊. (2011). Self-efficacy, goal orientations and learning strategies as mediators between preceding and subsequent academic achievement. Learning and Individual Differences, 21(2), 191-195. doi: 10.1016/j.lindif.2011.01.003

Eccles, J. S. (2005). Subjective task value and the Eccles et al. model of achievement-related choices. In A. J. Elliot \& C. S. Dweck (Eds.), Handbook of competence and motivation (pp. 105-131). New York, London: Guilford. 
Eccles, J. S., Midgley, C., Wigfield, A., Buchanan, C. M., Reuman, D., Flanagan, C., \& Mac Iver, D. (1993). Development during adolescence. The impact of stage-environment fit on young adolescents' experiences in schools and in families. American Psychologist, 48(2), 90-101. doi: $10.2307 / 1131221$

Eccles, J. S., \& Roeser, R. W. (2009). Schools, academic motivation, and stage $\square$ environment fit. In R. Lerner \& L. Steinberg (Eds.), Handbook of adolescent psychology (pp. 404-434). New York: Wiley.

Eccles, J. S., \& Wigfield, A. (2002). Motivational beliefs, values, and goals. Annual Review of Psychology, 53(1), 109-132. doi: 10.1146/annurev.psych.53.100901.135153

Elliot, A. J., \& Church, M. A. (1997). A hierarchical model of approach and avoidance achievement motivation. Journal of Personality and Social Psychology, 72(1), 218-232. doi: http://dx.doi.org/10.1037/0022-3514.72.1.218

Elliot, A. J., Elliot, A., \& Dweck, C. (2005a). A conceptual history of the achievement goal construct. In A. J. Elliot \& C. S. Dweck (Eds.), Handbook of competence and motivation (Vol. 16, pp. 52-72). New York, London: Guilford Press.

Elliot, A. J., Elliot, A., \& Dweck, C. (2005b). A conceptual history of the achievement goal construct. In A. J. Elliot \& C. S. Dweck (Eds.), Handbook of competence and motivation (Vol. 16, pp. 52-72).

Elliot, A. J., \& Harackiewicz, J. (1996). Approach and avoidance achievement goals and intrinsic motivation: A mediational analysis. Journal of Personality and Social Psychology, 70, 968980.

Elliott, E. S., \& Dweck, C. S. (1988). Goals: an approach to motivation and achievement. Journal of Personality and Social Psychology, 54(1), 5-12. doi: 10.1037/0022-3514.54.1.5 
Ferguson, C. J. (2009). An effect size primer: A guide for clinicians and researchers. Professional Psychology: Research and Practice, 40(5), 532-538. doi: http://dx.doi.org/10.1037/a0015808

Graber, J. A., Brooks-Gunn, J. E., \& Petersen, A. C. (1996). Transitions through adolescence: Interpersonal domains and context: Lawrence Erlbaum Associates, Inc.

Hamm, J. V., Farmer, T. W., Lambert, K., \& Gravelle, M. (2014). Enhancing peer cultures of academic effort and achievement in early adolescence: Promotive effects of the SEALS intervention. Developmental Psychology, 50(1), 216-228. doi: 10.1037/a0032979

Harackiewicz, J. M., Barron, K. E., Tauer, J. M., \& Elliot, A. J. (2002). Predicting success in college: A longitudinal study of achievement goals and ability measures as predictors of interest and performance from freshman year through graduation. Journal of Educational Psychology, 94(3), 562-575. doi: http://dx.doi.org/10.1037/0022-0663.94.3.562

Harter, S., Whitesell, N. R., \& Kowalski, P. (1992). Individual differences in the effects of educational transitions on young adolescent's perceptions of competence and motivational orientation. American Educational Research Journal, 29(4), 777-807.

Holopainen, L., \& Savolainen, H. (2005). The validity of self-reported grade point average. University of Joensuu and University of Jyväskylä, Finland. Jyväskylä, Finland.

Hu, L., \& Bentler, P. M. (1999). Cutoff criteria for fit indexes in covariance structure analysis: Conventional criteria versus new alternatives. Structural Equation Modeling: A Multidisciplinary Journal, 6(1), 1-55. doi: 10.1080/10705519909540118

Jacobs, J. E., Lanza, S., Osgood, D. W., Eccles, J. S., \& Wigfield, A. (2002). Changes in children's self $\square$ competence and values: Gender and domain differences across grades one through twelve. Child Development, 73(2), 509-527. doi: 10.1111/1467-8624.00421 
Koivisto, P., Vinokur, A. D., \& Vuori, J. (2011). Effects of career choice intervention on components of career preparation. The Career Development Quarterly, 59(4), 345-366. doi: 10.1002/j.2161-0045.2011.tb00074.x

Koivisto, P., Vuori, J., \& Vinokur, A. D. (2010). Transition to Work: Effects of Preparedness and Goal Construction on Employment and Depressive Symptoms. Journal of Research on Adolescence, 20(4), 869-892. doi: 10.1111/j.1532-7795.2010.00667.x

Leontopoulou, S. (2006). Resilience of Greek youth at an educational transition point: The role of locus of control and coping strategies as resources. Social Indicators Research, 76(1), 95126.

Little, T. D. (2013). Longitudinal Structural Equation Modeling. New York: Guilford Press.

Maaz, K., Trautwein, U., Lüdtke, O., \& Baumert, J. (2008). Educational transitions and differential learning environments: How explicit between $\square$ school tracking contributes to social inequality in educational outcomes. Child Development Perspectives, 2(2), 99-106.

Martin, A. J., \& Marsh, H. W. (2008). Academic buoyancy: Towards an understanding of students' everyday academic resilience. Journal of School Psychology, 46(1), 53-83.

Meichenbaum, D. (1985). Stress inoculation training: Pergamon.

Murphy, P. K., \& Alexander, P. A. (2000). A motivated exploration of motivation terminology. Contemporary Educational Psychology, 25(1), 3-53. doi: 10.1006/ceps.1999.1019

Muthén, L., \& Muthén, B. (1998-2010). Mplus user's guide. Los Angeles, CA: Muthen \& Muthen.

Niemivirta, M. (2002). Motivation and performance in context: The influence of goal orientations and instructional setting on situational appraisals and task performance. Psychologia, 45(4), 250-270. doi: http://doi.org/10.2117/psysoc.2002.250 
Niemivirta, M. (2004). Stability and change in middle school students' school value: An application of latent growth curve modeling. In A. Efklides, G. Kiosseoglou \& Y. Theodorakis (Eds.), Qualitative and quantitative research in psychology Athens, Greece: Ellinika Grammata.

Pajares, F., Britner, S. L., \& Valiante, G. (2000). Relation between achievement goals and selfbeliefs of middle school students in writing and science. Contemporary Educational Psychology, 25(4), 406-422. doi: 10.1006/ceps.1999.1027

Phillips, J. M., \& Gully, S. M. (1997). Role of goal orientation, ability, need for achievement, and locus of control in the self-efficacy and goal--setting process. Journal of Applied Psychology, 82(5), 792-802. doi: 10.1037/0021-9010.82.5.792

Pintrich, P. R. (2000). Multiple goals, multiple pathways: The role of goal orientation in learning and achievement. Journal of Educational Psychology, 92(3), 544-555. doi: 10.1037/00220663.92.3.544

Pintrich, P. R., Conley, A. M., \& Kempler, T. M. (2003). Current issues in achievement goal theory and research. International Journal of Educational Research, 39(4), 319-337. doi: 10.1016/j.jijer.2004.06.002

Preacher, K. J., \& Hayes, A. F. (2008). Asymptotic and resampling strategies for assessing and comparing indirect effects in multiple mediator models. Behavior Research Methods, 40(3), 879-891.

Rueger, S. Y., Malecki, C. K., \& Demaray, M. K. (2010). Relationship between multiple sources of perceived social support and psychological and academic adjustment in early adolescence: Comparisons across gender. Journal of Youth and Adolescence, 39(1), 47-61.

Salmela-Aro, K., Mutanen, P., Koivisto, P., \& Vuori, J. (2010). Adolescents' future educationrelated personal goals, concerns, and internal motivation during the "Towards Working Life" 
group intervention. European Journal of Developmental Psychology, 7(4), 445-462. doi: $10.1080 / 17405620802591628$

Salmela-Aro, K., Mutanen, P., \& Vuori, J. (2012). Promoting career preparedness and intrinsic work-goal motivation: RCT intervention. Journal of Vocational Behavior, 80(1), 67-75. doi: 10.1016/j.jvb.2011.07.001

Salmela-Aro, K., \& Nurmi, J.-E. (1997). Personal project appraisals, academic achievement and related satisfaction: A prospective study. European Journal of Psychology of Education, 12(1), 77-88. doi: 10.1007/BF03172871

Salmela-Aro, K., \& Vuori, J. (2015). School Engagement and Burnout Among Students: Preparing for Work Life. In J. Vuori, R. Blonk \& R. H. Price (Eds.), Sustainable working lives (pp. 5164). Dordrecht: Springer Netherlands.

Salmela $\square$ Aro, K., \& Upadyaya, K. (2014). School burnout and engagement in the context of demands-resources model. British Journal of Educational Psychology, 84(1), 137-151. doi: 10.1111/bjep.12018

Schiefele, U., \& Schaffner, E. (2015). Teacher interests, mastery goals, and self-efficacy as predictors of instructional practices and student motivation. Contemporary Educational Psychology, 42, 159-171. doi: 10.1016/j.cedpsych.2015.06.005

Schmitt, N. (1996). Uses and abuses of coefficient alpha. Psychological Assessment, 8(4), 350-353.

Schunk, D. H., \& Swartz, C. W. (1993). Goals and progress feedback: Effects on self-efficacy and writing achievement. Contemporary Educational Psychology, 18(3), 337-354. doi: 10.1006/ceps.1993.1024

Skaalvik, E. M. (1997). Self-enhancing and self-defeating ego orientation: Relations with task and avoidance orientation, achievement, self-perceptions, and anxiety. Journal of Educational Psychology, 89(1), 71-81. doi: http://dx.doi.org/10.1037/0022-0663.89.1.71 
Symonds, J., Dietrich, J., Chow, A., \& Salmela-Aro, K. (2016). Mental health improves after transition from comprehensive school to vocational education or employment in England: A national cohort study. Developmental Psychology, 52(4), 652-665. doi: http://dx.doi.org/10.1037/a0040118

Tanaka, J. S. (1993). Multifaceted conceptions of fit in structural equation models. In K. A. Bollen \& J. S. Long (Eds.), Testing structural equation models (pp. 10-39). Newbury Park, CA: Sage.

Tuominen-Soini, H., Salmela-Aro, K., \& Niemivirta, M. (2008). Achievement goal orientations and subjective well-being: A person-centred analysis. Learning and Instruction, 18(3), 251-266. doi: 10.1016/j.learninstruc.2007.05.003

Tuominen-Soini, H., Salmela-Aro, K., \& Niemivirta, M. (2011). Stability and change in achievement goal orientations: A person-centered approach. Contemporary Educational Psychology, 36(2), 82-100. doi: 10.1016/j.cedpsych.2010.08.002

Tuominen-Soini, H., Salmela-Aro, K., \& Niemivirta, M. (2012). Achievement goal orientations and academic well-being across the transition to upper secondary education. Learning and Individual Differences, 22(3), 290-305. doi: 10.1016/j.lindif.2012.01.002

Urdan, T. (1997). Achievement goal theory: Past results, future directions. In M. Maehr \& P. Pintrich (Eds.), Advances in motivation and achievement (Vol. 10, pp. 99-141). Greenwich, CT: JAI.

Urdan, T., \& Schoenfelder, E. (2006). Classroom effects on student motivation: Goal structures, social relationships, and competence beliefs. Journal of School Psychology, 44(5), 331-349.

Vandenberg, R. J., \& Lance, C. E. (2000). A review and synthesis of the measurement invariance literature: Suggestions, practices, and recommendations for organizational research. Organizational Research Methods, 3(1), 4-70. 
Vasalampi, K., Nurmi, J.-E., Jokisaari, M., \& Salmela-Aro, K. (2012). The role of goal-related autonomous motivation, effort and progress in the transition to university. European Journal of Psychology of Education, 27(4), 591-604.

Viljaranta, J., Kiuru, N., Lerkkanen, M.-K., Silinskas, G., Poikkeus, A.-M., \& Nurmi, J.-E. (2016). Patterns of word reading skill, interest, and self-concept of ability. Educational Psychology, 1-21. doi: $10.1080 / 01443410.2016 .1165798$

Vinokur, A. D., Price, R. H., \& Schul, Y. (1995). Impact of the JOBS intervention on unemployed workers varying in risk for depression. . American Journal of Community Psychology, 23, 39-74. doi: 10.1007/BF02506922

Vinokur, A. D., \& Schul, Y. (1997). Mastery and inoculation against setbacks as active ingredients in the JOBS intervention for the unemployed. Journal of Consulting and Clinical Psychology, 65(5), 867-877. doi: 10.1037/0022-006X.65.5.867

Vuori, J., \& Vinokur, A. D. (2005). Job $\square$ search preparedness as a mediator of the effects of the Työhön Job Search Interyention on re $\square$ employment and mental health. Journal of Organizational Behavior, 26(3), 275-291.

Wentzel, K. R. (1996). Social and academic motivation in middle school concurrent and long-term relations to academic effort. The Journal of Early Adolescence, 16(4), 390-406. doi: $10.1177 / 0272431696016004002$

Wolters, C. A., Shirley, L. Y., \& Pintrich, P. R. (1996). The relation between goal orientation and students' motivational beliefs and self-regulated learning. Learning and Individual Differences, 8(3), 211-238. doi: 10.1016/S1041-6080(96)90015-1

Wormington, S. V., \& Linnenbrink, E. A. (2016). A New Look at Multiple Goal Pursuit: The Promise of a Person-Centered Approach. Educational Psychology Review, in press. 
Zimmerman, B. J., Bandura, A., \& Martinez-Pons, M. (1992). Self-motivation for academic attainment: The role of self-efficacy beliefs and personal goal setting. American Educational Research Journal, 29(3), 663-676. doi: 10.3102/00028312029003663 


\section{MOTIVATIONAL PROCESSES ACROSS TRANSITION}

\section{Tables.}

Table 1

Model Fit Indices for Measurement Invariance Testing (Full Sample/Girls/Boys)

\begin{tabular}{|c|c|c|c|c|c|c|c|c|}
\hline Full sample & $\chi^{2}$ & $d f$ & $\Delta \chi^{2}$ & $\Delta d f$ & CFI & TLI & RMSEA & SRMR \\
\hline 1 & 541.868 & 293 & - & - & .96 & 0.95 & 0.038 & .044 \\
\hline 2 & 569.560 & 302 & $28.02 *$ & 9 & .95 & 0.94 & 0.039 & .049 \\
\hline $2 \mathrm{a}$ & 556.972 & 301 & 15.13 & 8 & .96 & 0.95 & 0.038 & .046 \\
\hline 3 & 659.496 & 315 & $112.76^{*}$ & 14 & .94 & & 0.043 & .050 \\
\hline $3 a$ & 570.799 & 309 & 13.79 & 8 & .96 & 0.95 & 0.038 & .047 \\
\hline 4 & 956.664 & 567 & & & & 0.94 & 0.034 & .047 \\
\hline
\end{tabular}

Note . CFI = comparative fit index; TLI = Tucker-Lewis index; RMSEA = root mean square error of approximation; SRMR = standardized root mean residual. $1=$ no equality constraints but configural invariance; $2=$ loadings invariant across time; $2 \mathrm{a}=$ loadings partially invariant across time; $3=$ loadings partially invariant and intercepts invariant across time; $3 \mathrm{a}=$ loadings and intercepts partially invariant across time; 4 = measurement model including (partial) time invariance restrictions and all latent factors, also those that were only measured at Time 1 .

${ }^{*} p<.05 . * * p<.01 . * * * p<.001$. 
Table 2

Range of Standardized Factor Loadings ( $\lambda$ min.-max.) for Latent Factors in the Full Sample

\begin{tabular}{llll}
\hline Latent factor & Time 1 & Time 2 & Time 3 \\
\hline Self-efficacy beliefs & $.462-.810$ & & \\
Inoculation against setbacks & $.577-.643$ & $.786-.843$ & \\
Mastery orientation & $.817-.857$ & $.607-.775$ & $.804-.826$ \\
Performance-approach orientation & $.576-.765$ & $.857-.919$ \\
Performance-avoidance orientation & $.759-.789$ & $.805-.922$ & $.481-.924$ \\
Effort & & $.489-.925$ & \\
School value & & &
\end{tabular}

Note. $N=687$. Standardized latent factor loadings are reported from the final measurement model in Table 1 step 4a. 
Table 3

Intercorrelations between the Study Variables

\begin{tabular}{|c|c|c|c|c|c|c|c|c|c|c|c|c|c|}
\hline & 1 & 2 & 3 & 4 & 5 & 6 & 7 & 8 & 9 & 10 & 11 & 12 & 13 \\
\hline \multicolumn{14}{|l|}{ 1. Boys } \\
\hline 2. GPA & $-.16^{* * *}$ & & & & & & & & & & & & \\
\hline 3. Self & .02 & .01 & & & & & & & & & & & \\
\hline 4. Inoc & $-.11 *$ & -.03 & $.32 * * *$ & & & & & & & & & & \\
\hline 5. PpT1 & .04 & $.25 * * *$ & $.14^{*}$ & .09 & & & & & & & & & \\
\hline 6. РpT2 & -.04 & .06 & -.01 & -.01 & $.49 * * *$ & & & & & & & & \\
\hline 7. PvT1 & -.05 & -.06 & $-.18 * * *$ & -.01 & $.54 * * *$ & $.26 * * *$ & & & & & & & \\
\hline 8. PvT2 & $-.13 * * *$ & -.05 & $-.22 * * *$ & -.07 & $.28 * * *$ & $.66 * * *$ & $.50 * * *$ & & & & & & \\
\hline 9. MaT1 & .01 & $.28 * * *$ & $.38 * * *$ & $.15^{*}$ & $.33 * * *$ & -.01 & .02 & -.08 & & & & & \\
\hline 10. MaT2 & $-.11 *$ & $.19 * * *$ & $.34 * * *$ & .10 & & $.15^{* *}$ & $-.13 * *$ & -.10 & $.47 * * *$ & & & & \\
\hline 11. SVT2 & $-.27 * * *$ & $.28 * * *$ & $.12 *$ & & .08 & $-.31 * * *$ & $-.12 *$ & $-.34 * * *$ & $.20 * * *$ & $.40 * * *$ & & & \\
\hline 12. SVT3 & $-.30 * * *$ & $.29 * * *$ & $.17 * * *$ & .08 & .02 & -.09 & -.11 & $-.12 *$ & $.35 * * *$ & $.43 * * *$ & $.63 * * *$ & & \\
\hline 13. EffT2 & -.01 & -.03 & & .09 & .07 & .06 & .03 & .05 & $.23 * * *$ & $.35 * * *$ & .08 & $.14 * * *$ & \\
\hline 14. EffT3 & -.05 & -.02 & & .12 & .05 & .02 & .02 & -.10 & $.17 * * *$ & $.28 * * *$ & .10 & $.25 * * *$ & $.42 * * *$ \\
\hline
\end{tabular}


Note. $N=588$. Self $=$ self-efficacy beliefs; Inoc $=$ inoculation against setbacks; $\mathrm{Pp}=$ performance-approach; Pv $=$ performanceavoidance; $\mathrm{Ma}=$ mastery; Eff = effort; SV = school value. Standardized latent correlations are reported for latent variables. $* p<.05 . * * p<.01 . * * * p<.001$. 
Table 4

Standardized Regression Coefficients for the Full Sample

\begin{tabular}{|c|c|c|c|c|c|c|c|}
\hline Variable & MaT2 & PpT2 & PvT2 & SVT2 & EffT2 & SVT3 & EffT3 \\
\hline Boys & $-.111 * * \quad(0.04)$ & $-.045 \quad(0.04)$ & $-.098 * *(0.03)$ & $-.249 * * *(0.04)$ & $-.008 \quad(0.05)$ & $-.115 * \quad(0.05)$ & $-.057(0.04)$ \\
\hline GPAT1 & $.045 * * *(0.01)$ & $.014 \quad(0.01)$ & $.019 \quad(0.01)$ & $.204 * * *(0.04)$ & -.038 & $.116 * * *(0.03)$ & $-.020(0.04)$ \\
\hline Self & $.226 * * *(0.06)$ & $-.079 \quad(0.06)$ & $-.134 *(0.06)$ & $.156 * * \quad(0.06)$ & $-.213 * * *(0.06)$ & $\gamma$ & \\
\hline Inoc & $-.030 \quad(0.06)$ & $-.022 \quad(0.07)$ & $-.031(0.06)$ & $(0.07)$ & $(0.06)$ & & \\
\hline MaT1 & $.354 * * *(0.05)$ & & & & & $.225 * * * *(0.05)$ & $.121 *(0.06)$ \\
\hline PpT1 & & $.452 * * *(0.05)$ & & & & $(0.10)$ & $.063 \quad(0.08)$ \\
\hline PvT1 & & & $.458 * * *(0.04)$ & & & $(0.09)$ & $-.130 \quad(0.08)$ \\
\hline \multicolumn{8}{|l|}{ MaT2 } \\
\hline \multicolumn{8}{|l|}{ РpT2 } \\
\hline \multicolumn{8}{|l|}{ PvT2 } \\
\hline SVT2 & & & & & & $.486 * * *(0.08)$ & \\
\hline EffT2 & & & & & & & $.378 * * *(0.06)$ \\
\hline
\end{tabular}

Note. $N=588$. GPA = self-reported grade point average; Self = self-efficacy; Inoc $=$ fear of failure; Ma = mastery goal orientation; Pp

= performance-approach goal orientation; $\mathrm{Pv}=$ performance-avoidance goal orientation; $\mathrm{SV}=$ school value; Eff = effort.

$* p<.05 . * * p<.01 . * * * p<.001$. 


\section{Before transition}

Age 15

Comprehensive school
After transition year 1 Age 16

Upper secondary school
After transition year 2

Age 17

Upper secondary school

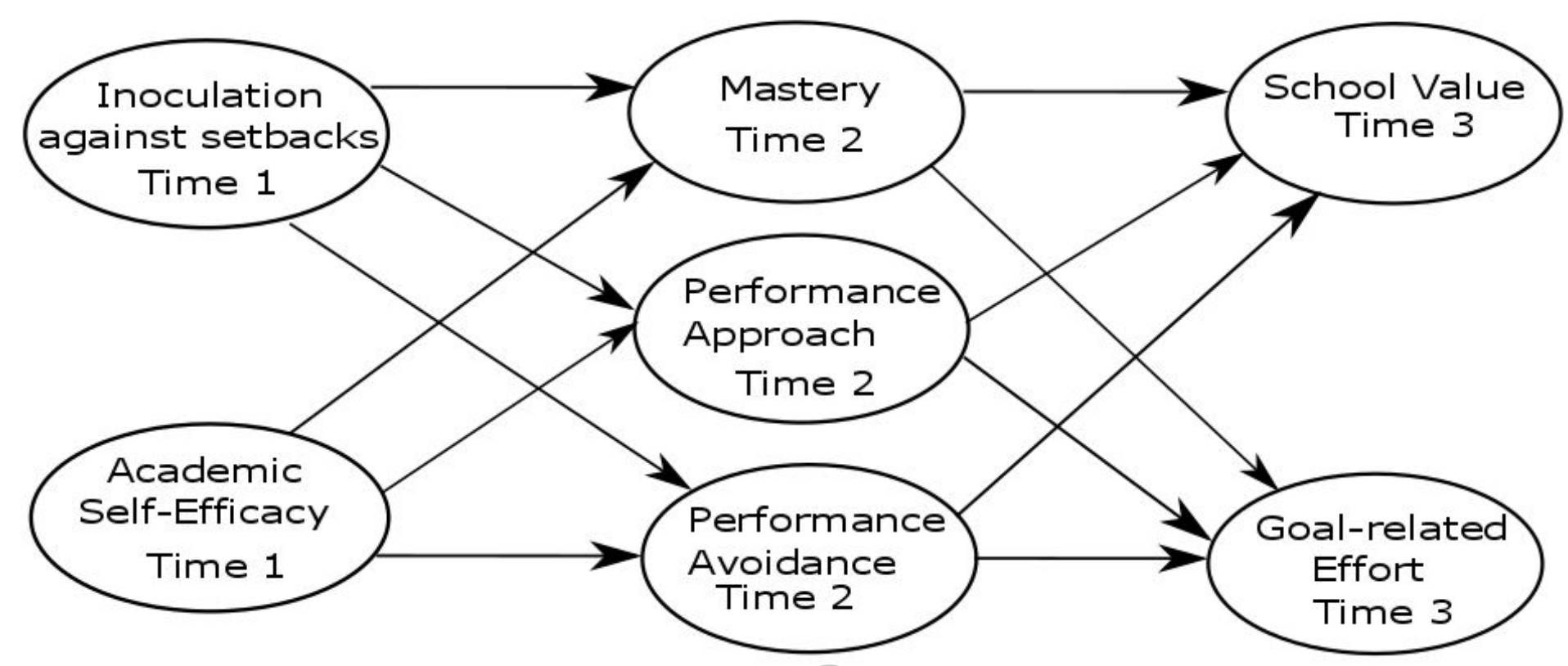

Figure 1. Hypothesized model of the relationships between self-efficacy beliefs and inoculations against setbacks at Time 1, achievement goal orientations at Time 2, and school value and goal-related effort at Time 3. Adolescents' gender, self-reported GPA and achievement goal orientations at Time 1 as well as their school value and goal-related effort at Time 2 were also included as predictors. 


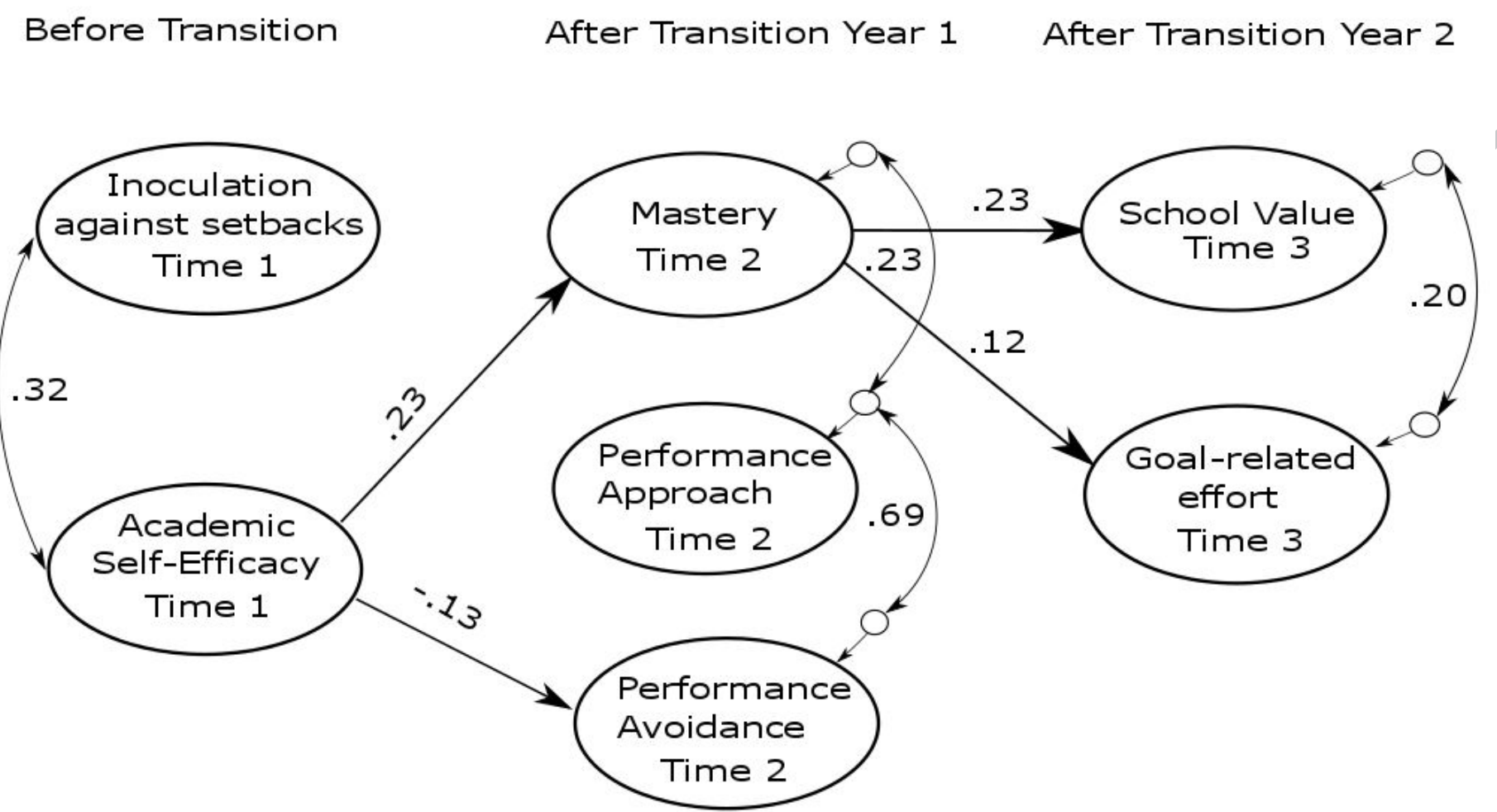

Figure 2. Relationships between self-efficacy beliefs and academic fear of failure at Time 1, achievement goal orientations at Time 2 , and school value and academic withdrawal at Time 3. Adolescents' gender, self-reported GPA and achievement goal orientations at Time 1 as well as their school value and academic withdrawal at Time 2 were also included as predictors, but for reasons of clarity, coefficients are only reported in-text. Displayed paths are standardized and significant at least at $p<.05$. 


\section{Appendix}

A) Measurement invariance testing

In the full sample, one loading of the latent factor school value varied across time. The wording of item no. 3 was "I think going to school is a waste of time.". Standardized factor loading at Time 1 was $\lambda=0.926$ and at Time 2 was $\lambda=0.701$. Overall, six item intercepts varied across time. Of the latent factor mastery goal orientation, two item intercepts varied across time. The wording of item no. 2 was “An important goal for me in my studies is to learn as much as possible.". Intercept values were for this item at Time $1 M=3.54(0.12)$ and at Time $2 M=4.25(0.13)$. The wording of item no. 3 was "To acquire new knowledge is an important goal for me in school". Intercept values were for this item at Time $1 M=3.79(0.13)$ and at Time $2 M=4.04(0.12)$. One item intercept of the latent factor performance-approach goal orientation varied across time. The wording of item no. 2 was "I feel I have attained my goal if I get better results or grades than many other students.". Intercept values were for this item at Time $1 M=2.36(0.06)$ and at Time $2 M=2.21(0.07)$. Two item intercepts of the latent factor goal-related effort' varied across time. The wording of item no. 1 was "How much time and effort have you spent on this goal?" and for item no. 2 "To what extent have you worked for your goal?". Intercept values were for item no. 1 at Time $1 M=3.45(0.11)$ and at Time $2 M=3.67(0.14)$. Intercept values were for item no. 2 at Time $1 M=3.80(0.13)$ and at Time $2 M=3.82(0.12)$. One item intercept of the latent factor 'school value' varied across time. The wording of item no. 3 was 'I think going to school is a waste of time'. Intercept values were for this item at Time $1 M=4.59(0.23)$ and at Time $2 M=5.67(0.27)$. 


\section{B) Moderation analyses}

In this study, in line with the comments of a reviewer, we conducted latent interaction analyses and examined whether self-efficacy beliefs and inoculation at Time 1 moderate the effects of achievement goal orientations at Time 1 on school value and goal-related effort at Time 2 (and Time

3). Furthermore, it was tested whether self-efficacy beliefs moderate the effect of inoculation against setbacks at Time 1 on school value and goal-related effort at Time 2 (and Time 3). The findings demonstrated a statistically significant interaction between adolescents' self-efficacy beliefs related to educational choices and the adolescents' performance-approach goal orientation before the transition (Time 1) on their school value 1 year after the transition (Time 2) when controlling for school value before the transition $(b=.055, S E=.03, p<.05,95 \%$ CI $[.000, .110])$. Simple slope analyses showed that performance-approach goal orientation before the educational transition had a statistically significant and negative effect on school value after the transition only for adolescents with low levels of self-efficacy related to educational choices (low: $\beta=-.151$, SE $=.07, p<.05$; medium: $\beta=-.064, S E=.03, p<.05$; high: $\beta=.023, S E=.07, p=.09)$. 


\section{Highlights}

- A concept of preparedness for educational transitions was tested

- Self-efficacy beliefs positively predict mastery orientation after the transition

- Self-efficacy beliefs negatively predict performance avoidance orientation

- Mastery orientation predict school value and effort 